\title{
The Lagged Effect Of Basic Employment Changes In A Regional Economy\#
}

\author{
Thomas H. Spreen and W. David Mulkey** \\ INTRODUCTION
}

Since being introduced in the 1920's, economic base relationships or some variation of the basic-non basic theme have been widely used in impact analysis and various regional forecasting applications. Conventional studies begin by allocating regional employment between a basic (export) sector and a local service sector (Tiebout, Bendavid, Richardson). The estimated relationship is then assumed to remain unchanged, and the resulting aggregate multiplier is used to assess the total impact of any change in the basic sector.

Previous studies have paid little, if any attention to the time dimension of the basic-non basic relationship. The traditional view has been that the basic-non basic relationship is short-run (Williamson). This view has been contradicted by results reported by Moody and Puffer and McNulty which support a longer run interpretation. Thus the literature provides no consensus on the time dimension issue.

A second, more fundamental, issue has also received little attention in the literature. Most studies (to our knowledge) assume that changes in basic employment cause changes in total employment and do not explicitly test for the existence of the posited relationship. Relatively new statistical techniques are now available to allow empirical testing of the basic-non basic hypothesis.

The objective of this paper is to test empirically for the existence and nature of the hypothesized relationship between basic and total employment. The approach taken is non-traditional in terms of defining causality. The discussion proceeds in the next section by defining the concept of causality. Next, statistical tests are employed to test for the existence of a causal relationship between basic and total employment using quarterly employment data from five Southeastern states. The results are presented and tenative conclusions are drawn.

\section{DEFINING AND TESTING CAUSAL RELATIONSHIPS}

Consider two time ordered variables (time series data) $Y_{t}$ and $X_{t}$. Granger argues that $Y_{t}$ is caused by $X_{t}$ if we are better able to predict $Y_{t}$

\#Florida Agricultural Experiment Station Journal Series 2579.

**The authors are Assistant Professors, Department of Food and Resource Economics, University of Florida, Gainesville, Florida. 
using all available information than if the information apart from $\mathrm{X}_{\mathrm{t}}$ had been used.

This prediction oriented definition of causality is simple conceptually but is subject to the major deficiency that rarely is it possible to include all relevant information in predicting $\mathrm{Y}_{\mathrm{t}}$. To simplify matters, a simple definition is proposed which states $X_{t}$ causes $Y_{t}$ if knowledge of $X_{t}$ can improve the prediction of $Y_{t}$ compared to the prediction of $Y_{t}$ taking into account the past history of $\mathrm{Y}_{\mathrm{t}}$ alone.

Causality may be unidirectional or have feedback, and be instantaneous or delayed. To indicate unidirectional causality we write $X_{t-j} \rightarrow Y_{t}$ for $j>0$ $(j=0$ implies an instantaneous relationship). Feedback between two series is denoted by $X_{t} \longleftrightarrow Y_{t}$ and occurs when current, lagged, and future $Y$ causes and is caused by current, lagged and future X.

Granger and Sims both have proposed tests to determine the exact nature of the relationship between two time series. In a more complete study their tests should be included. ${ }^{1}$ In this paper, however, we employ only the methodology proposed by Haugh and expanded and utilized by Pierce, which we refer to as the Haugh-Pierce Method.

The Haugh-Pierce method consists of two steps. First univariate ARIMA (integrated autoregressive-moving average) models are estimated for each of the time series utilizing the method proposed by Box and Jenkins. The Box-Jenkins technique assumes that both series are stationary and if not, the series are differenced to achieve stationarity. ${ }^{2,3}$

Assume that the univariate models for each series may be represented by:

$$
\begin{aligned}
& \text { (1) } F(B) X_{t}=U_{t} \\
& \text { (2) } G(B) Y_{t}=V_{t}
\end{aligned}
$$

where $F(B)$ and $G(B)$ are invertible polynomials in the operator $B^{4}$ (the filters), and $U_{t}$ and $V_{t}$ are white noise processes with variances $\sigma_{u}^{2}$ and $\sigma_{v}^{2}$, respectively. The noise process $U_{t}$ represents that part of $X_{t}$ which cannot be explained by the past history of $\mathrm{X}_{\mathrm{t}}$ alone. Similarly, $\mathrm{V}_{\mathrm{t}}$ represents the part of $Y_{t}$ which cannot be explained by the past history of $Y_{t}$ alone. $U_{t}$ and $\mathrm{V}_{\mathrm{t}}$ are sometimes referred to as the innovations.

The second step of the Haugh-Pierce method is to examine cross correlations of $U_{t}$ and $V_{t}$. The cross correlation between $U_{t}$ and $V_{t}$ at lag $k$ is given by:

$$
\text { (3) } \rho_{\text {uv }}(\mathrm{k})=\frac{\mathrm{E}\left(\mathrm{U}_{\mathrm{t}-\mathrm{k}}, \mathrm{V}_{\mathrm{t}}\right)}{\left[\mathrm{E}\left(\mathrm{U}_{\mathrm{t}}\right)^{2} \mathrm{E}\left(\mathrm{V}_{\mathrm{t}}\right)^{2}\right]^{1 / 2}}
$$

In actuality, $\mathrm{u}$ and $\mathrm{v}$ are not observable, but are replaced by their estimated values from (1) and (2) which gives $r \hat{u} \hat{v}(k)$, the sample counterpart of (3). Under the null hypothesis that $\mathrm{X}$ and $\mathrm{Y}$ are independent, Haugh has shown that $\hat{r} \hat{u} \hat{v}(k)$ is asymptotically independently and normally distri- 
TABLE 1

Prewhitening Models

\begin{tabular}{ccrr}
\hline State & $\begin{array}{c}\text { Employment } \\
\text { Series }\end{array}$ & \multicolumn{1}{c}{ Model } & $\mathrm{X}^{2 \mathrm{a}}$ \\
\hline South & Basic & $(1-\mathrm{B}) \mathrm{Yt}=(1-.53 \mathrm{~B}) \mathrm{Ut}$ & 11.99 \\
Carolina & Total & $(1-\mathrm{B}) \mathrm{Yt}=(1-.44 \mathrm{~B}) \mathrm{Ut}$ & 4.99 \\
Alabama & Basic & $(1-\mathrm{B})\left(1-\mathrm{B}^{4}\right) \mathrm{Yt}=(1-.96 \mathrm{~B}) \mathrm{Ut}$ & 5.36 \\
& Total & $(1-\mathrm{B})\left(1-\mathrm{B}^{4}\right) \mathrm{Yt}=(1-.72 \mathrm{~B}) \mathrm{Ut}$ & 8.81 \\
Georgia & Basic & $(1-\mathrm{B})\left(1-\mathrm{B}^{4}\right) \mathrm{Yt}=\left(1-.92 \mathrm{~B}^{4}\right) \mathrm{Ut}$ & 2.61 \\
& Total & $(1-\mathrm{B})\left(1-\mathrm{B}^{4}\right) \mathrm{Yt}=\left(1-.64 \mathrm{~B}^{4}\right) \mathrm{Ut}$ & 6.69 \\
North & Basic & $\left(1-\mathrm{B}\left(1-\mathrm{B}^{4}\right) \mathrm{Yt}=\left(1-.83 \mathrm{~B}^{4}\right) \mathrm{Ut}\right.$ & 11.97 \\
Carolina & Total & $(1-\mathrm{B})\left(1-\mathrm{B}^{4}\right) \mathrm{Yt}=\left(1-.61 \mathrm{~B}^{4}\right) \mathrm{Ut}$ & 15.91 \\
Florida & Basic & $(1-\mathrm{B}) \mathrm{Yt}_{\mathrm{t}}=4.1+8.4 \cos (\pi \mathrm{t} / 2)+8.4 \sin (\pi \mathrm{t} / 2)$ & 10.51 \\
& Total & $(1-\mathrm{B}) \mathrm{Yt}=21.4+29.5 \cos (\pi \mathrm{t} / 2)+49.9 \sin (\pi \mathrm{t} / 2)$ & 12.78 \\
\hline
\end{tabular}

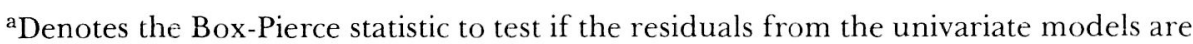
white noise, using the first 20 autocorrelations of the residual series. The tabulated $\mathrm{X}^{2}$ statistic with 20 degrees of freedom at the 50th percentile is 19.3 indicating that the residuals from all ten models can be considered white noise with a high degree of confidence.

buted with mean zero and variance $\mathrm{T}^{-1}$, where $\mathrm{T}$ is the number of observations used to calculate $\mathrm{r} \hat{u} \hat{v}(\mathrm{k})$.

Once the residual cross correlation estimates have been calculated, statistical tests of significance for individual estimates are obtained by the criterion that sample cross correlations exceed their approximate standard deviations by a factor of two. That is:

(4) $\quad \mathrm{R}_{\mathrm{uv}}^{\hat{n}}(\mathrm{k}) \geqslant 2 \mathrm{~T}^{-1 / 2}$

indicates a significant cross correlation. Individual significant crosscorrelations may then be used to detect causal directions at specific lags.

An overall test of significance to determine whether joint dependence exists between the two series takes the form of a chi-square statistic. Given Haugh's results on the distribution of the $\hat{r}(k)$, this statistic is defined as:

(5) $Q_{x, y}=T_{k} \underset{k}{\sum}\left[\hat{r_{u v}}(k)\right]^{2}$

The two series are said to be independent at the $\alpha$ level if $\mathrm{Q}_{\mathrm{x}, \mathrm{y}}<\mathrm{X} \alpha, 2 \mathrm{~m}+1$ where $2 m+1$ is the appropriate degrees of freedom for the tabled chisquare statistic.

Similarly, tests of unidirectional causality have been suggested (Pierce) using the following statistics:

$$
\text { (6) } Q_{\mathrm{x}} \rightarrow_{\mathrm{y}}=\mathrm{T} \underset{\mathrm{k}=1}{\mathrm{~m}}\left[\mathrm{r}_{\mathrm{uv}}(\mathrm{k})\right]^{2}
$$


indicates X causes (leads) $\mathrm{Y}$ at the $\alpha$ level of significance if it exceeds $\mathrm{X}^{2}{ }_{\text {,m }}$ and,

$$
\text { (7) } \left.Q_{\mathrm{y}} \rightarrow_{\mathrm{x}}=\mathrm{T}_{\mathrm{k}=-1} \sum_{\mathrm{uv}}^{-\mathrm{m}}[\mathrm{k})\right]^{2}
$$

indicates Y causes (leads) $\mathrm{X}$ at the $\alpha$ level of significance if it exceeds $\mathrm{X}_{\boldsymbol{\alpha}}^{2}{ }_{, \mathrm{m}}$.

\section{Empirical Results}

Five Southeastern states were selected consisting of Alabama, Georgia, Florida, North Carolina, and South Carolina. Quarterly employment data for eight sectors (Mining; Construction; Manufacturing, Utilities; Retail Trade; Finance; Services; and Government) were collected for the period 1955-1974. Employment was allocated between the basic and nonbasic sectors using location quotients. The location quotients were calculated each year using annual average employment in each state and comparable national employment data from the U.S. Department of Labor.

To initiate the Haugh-Pierce procedure, univariate ARIMA models were estimated for each employment series for each state. These models are summarized in Table 1. All ten series required first differencing to achieve stationarity. Except for South Carolina which had no seasonal component, fourth differences of the first differences (i.e. $\left[\mathrm{X}_{\mathrm{t}}-\mathrm{X}_{\mathrm{t}-1}\right]-$ $\left[\mathrm{X}_{\mathrm{t}-4}-\mathrm{X}_{\mathrm{t}-5}\right]$ ) were computed to remove a strong seasonal component from the data. For Alabama, Georgia, and North Carolina, simple moving average models were estimated. Even after computing fourth differences, a seasonal component still remained in the Florida data. After some experimentation, trigonometric functions in time were found to fit the Florida series adequately. The highly seasonal nature of the Florida data is not surprising considering the impact of tourists and the annual migration of retirees.

TABLE 2

Cross Correlation Analysis

\begin{tabular}{lccc}
\hline \multicolumn{1}{c}{ State } & $\begin{array}{c}\text { Basic leads }^{\mathrm{a}} \\
\text { Total }^{\text {Soth }}\end{array}$ & $\begin{array}{c}\text { Total leads }^{\mathrm{b}} \\
\text { Basic }\end{array}$ & $\begin{array}{c}\text { Zero } \\
\text { lag }\end{array}$ \\
\hline South Carolina & 5.61 & 5.50 & $.919^{\mathrm{d}}$ \\
Alabama & $19.28^{\mathrm{c}}$ & 7.34 & .071 \\
Georgia & 2.90 & 8.64 & .051 \\
North Carolina & 13.80 & 10.16 & $.288^{\mathrm{d}}$ \\
Florida & 16.65 & 6.28 & $.605^{\mathrm{d}}$ \\
\hline
\end{tabular}

${ }^{\mathrm{a} C}$ Calculated $Q$ statistic over twelve lags (eq. 6)

${ }^{\mathrm{b}}$ Calculated $Q$ statistic over twelve lags (eq. 7)

'Significant at the .10 level

dSignificant at the .01 level 
The residuals from the univariate models for basic and total employment in each state were cross correlated. Q statistics, testing for unidirectional causality were calculated and the results are presented in Table 2 . Of the five states, a weak $(\alpha=.10)$ causal relationship was found between basic and total employment in only Alabama. Examination of the individual Alabama cross-correlations revealed that only the eighth and ninth lags were significantly different from zero.

The third column of Table 2 shows the cross correlation at lag zero. For three of the five states, the zero lag cross correlation coefficient is significantly different from zero.

\section{Concluding Remarks}

The results provide little support for the use and accuracy of aggregate base multipliers in short run models. In four of the five states examined, the null hypothesis that basic employment does not cause total employment could not be rejected. An instantaneous relationship between basic and total employment was found in three of the five states but this is contrary to the expected lagged relationship between basic and total employment.

The failure to find a relationship between basic and total employment could be attributed to one or more reasons: 1) State data is not appropriate and smaller, more homogenous regions such as SMSA's should be considered, 2) income is a more appropriate measure of economic activity than employment, 3) the location quotient method does not accurately estimate basic employment, or, 4) the basic-total phenomenon is not a short-run relationship as was pursued in this paper. The authors recognize the need to examine each of these issues before any definitive statement can be made concerning the general validity of economic base theory.

\section{FOOTNOTES}

${ }^{1}$ There are certain empirical difficulties with the Granger and Sims tests which have been discussed by Feige and Pearce.

${ }^{2}$ Stationarity implies that the series possesses a time invariant mean and variance.

${ }^{3}$ Differencing usually involves first differencing the data.

${ }^{4}$ That is $\mathrm{F}(\mathrm{B})=1-\phi_{1} \mathrm{~B}-\phi_{2}-\ldots$ and $\mathrm{G}(\mathrm{B})=1-\gamma_{1} \mathrm{~B}-\gamma_{2} \mathrm{~B}^{2} \ldots$ where $(1-\mathrm{B}) \mathrm{X}_{\mathrm{t}}=\mathrm{X}_{\mathrm{t}}-\mathrm{X}_{\mathrm{t}-1}$

\section{REFERENCES}

Bendavid, Avrom. Regional Economics for Practitioners: An Introduction to Common Descriptive Methods. New York: Praeger Publishers, 1974

Box, G. E. P. and G. M. Jenkins. Time Series Analysis Forecasting and Control. San Francisco: Holden Day, 1970.

and David A. Pierce. "Distribution of Residual Autocorrelations in Autoregressive - Integrated Moving Average Time Series Models." Journal of the American Statistical Association 65 (December 1970): 1509-26.

Feige, Edgar L. and Douglas K. Pearce. "The Casual Causal Relationship Between Money and Income: Some Caveats for Time Series Analysis." Review of Economics and Statistics 61 (November 1979): 521-533.

Granger, C. W. J. "Investigating Causal Relations by Econometric Models and Cross Spectral Methods." Econometrica 37 (July 1969): 424-438.
Haugh, Larry D. "The Identification of Time Series Interrelationships with Special Reference to Dynamic Regression." Unpublished Ph.D. dissertation. University of Wisconsin-Madison 1972

McNulty, James E. "A Test of the Time Dimension in Economic Base Analysis." Land Economics 53 (August 1977): 359-368

Moody, Harold T. and Frank W. Puffer. "The Empirical Verification of the Urban Base Multiplier: Traditional and Adjustment Process Models." Land Economics 46 (February 1970): 91-98.

Pierce, David A. "Relationships - and the Lack Thereof - Between Economic Time Series with Special Reference to Money and Interest Rates." Journal of the American Statistical Association 72 (March 1977): 11-22. 
Richardson, Harry W. "The State of Regional Economics: A Survey Article," International Regional Science Review 3 (Fall 1978): 1-48.

Sims, Christopher A. "Money, Income and Causality." American Economic Review 62 (September 1972): 540552.

Spreen, Thomas H. and W. David Mulkey. "The Lagged Effect of Basic Employment Changes in the Florida
Economy." Contributed paper, Southern Regional Science Association meetings, Nashville, Tennessee, April 1979.

Tiebout, Charles M. The Community Economic Base Study. Supplementary Paper No. 16, New York: Committee for Economic Development, 1962.

Williamson, Robert B. "Predictive Power of the Export Base Theory." Growth and Change 6 (January 1975): 3-10. 